\title{
Creating Community Resilience Through Elder-Led Physical and Social Infrastructure
}

\author{
Daniel P. Aldrich, PhD; Emi Kyota, PhD
}

\section{ABSTRACT}

Objective: Natural disasters and rapidly aging populations are chronic problems for societies worldwide. We investigated the effects of an intervention in Japan known as Ibasho, which embeds elderly residents in vulnerable areas within larger social networks and encourages them to participate in leadership activities. This project sought to deepen the connections of these elderly residents to society and to build elderly leadership and community capacity for future crises.

Methods: We carried out surveys of participants and nonparticipant residents across the city of Ofunato in Tohoku, Japan, 1 year after the intervention began. Our surveys included questions assessing participation levels in Ibasho, demographic characteristics, efficacy, social networks, and a sense of belonging.

Results: Regression analysis and propensity score matching of more than 1100 respondents showed that regular participation in the Ibasho project had a statistically significant and positive connection with various measures of social capital.

Conclusions: Given its relatively low cost and focus on deepening cohesion, we suggest that this community-based project could be replicated and scaled up in other countries to deepen resilience, elder health, and social capital. Moving away from an emphasis on investing in physical infrastructure, we believe that disaster risk reduction strategies should center on social infrastructure. (Disaster Med Public Health Preparedness. 2017;11:120-126)

Key Words: social capital, elderly, tsunami, Great East Japan Earthquake, disaster

$\mathrm{W}$ hile terrorism and other high-profile events regularly dominate the media cycle, natural disasters and a rapidly aging population serve as more pressing chronic problems for developing and developed countries alike. A number of recent disasters have driven home the urgency of disaster risk management. These all-too-regular events have simultaneously underscored how the financial costs and loss of life from disasters have risen over the past decade. ${ }^{1}$ At the same time, societies such as Germany, Italy, and Japan face the challenge of the "graying problem," with more than $20 \%$ of their populations aged over 65 years. Some 20 other countries, primarily among the developed Organization for Economic Cooperation and Development nations, will join in this statistic by 2030. Beyond the financial challenges of ensuring that a decreasing number of younger workers can continue to support welfare systems focused on larger numbers of retirees, societies must ensure access for the elderly to physical infrastructure and provide sufficient health care support. These twin challenges of aging and disaster mitigation have no simple technical solution and require multichannel, multiple stakeholder approaches.
This article provides evidence about the efficacy of a program that alters our perspective on the role of the elderly and enhances resilience to future catastrophes. The bottom-up intervention known as Ibasho (literally "one's place" in Japanese) embeds elderly residents in vulnerable areas within larger social networks and encourages them to participate in leadership activities. Based in a physical structure with flexible space that can be used, among other activities, as a library, café, and meeting spot, Ibasho brings people together who may otherwise have limited social contact. In doing so, the program reduces a community's vulnerability to future disasters and builds broader resilience in the face of crises, as much research has emphasized the mitigating role of deeper reservoirs of social capital. This article provides empirical evidence from quantitative data that this intervention has enhanced feelings of efficacy, broadened social networks, and deepened the sense of belonging among frequent participants.

This article contributes to the resilience and elder-care literature in several ways. First, it used a quantitative analysis to measure the impact of an intervention designed to increase social capital and resilience. 
Beyond regression coefficients, we provide easy-to-read, visual representation of the relationships between key variables of interest and our degree of certainty. ${ }^{2}$ Next, Ibasho's bottom-up, elderly-managed approach is radically at odds with standard visions of resilience programming. Typically, governments and private actors prepare for natural disasters by investing in large-scale, top-down physical infrastructure projects such as seawalls, levees, berms, and other expensive construction projects. Here we emphasize a new framework for intervention based at the community level to ensure buy-in from residents and also continuity over time. Finally, our quantitative evidence about the efficacy of a social capital building intervention suggests obvious concrete policy recommendations for other field sites and communities around the world.

\section{Theory}

Past research has shown that social connections and social infrastructure strongly condition resilience, disaster outcomes, and disaster recovery. ${ }^{3-5}$ Here we focus on social capital, the connections between individuals that allow them to more easily work collectively, share norms, and exchange information. ${ }^{6}$ Scholars have differentiated bonding social capital, which connects similar individuals, from bridging social capital (that connects people who are different, often through schools, workplaces, or clubs) and linking social capital (that connects residents with those in authority). ${ }^{7,8}$

Across these types of connections, individuals and neighbors with deeper reservoirs of social capital will have more trust, belief in their ability to alter their policy environment, and a stronger sense of belonging. ${ }^{9}$ Cohesive and integrated communities will also be better able to survive major collective trauma, such as a natural or natural-technological disaster and then recover at a faster pace than less cohesive neighborhoods. ${ }^{10}$ Coastal communities in Tohoku, Japan, for example, that had greater trust and interaction before the 3/11 tsunami had lower mortality rates than did similar but less cohesive areas during the crisis. ${ }^{11}$

The Ibasho project builds on the beliefs that elder-led, community-centered projects not only empower the elderly but simultaneously build bonding social capital and develop community resilience to future crises. ${ }^{12}$ By placing decisionmaking power in the hands of those with the most experience, and encouraging the elderly to play active rather than passive roles in the community, Ibasho helps to change narratives about aging and to better prepare communities for future shocks. The pilot Ibasho project in Japan centers in a physical space placed close to a field of temporary houses occupied by survivors of Tohoku's Great East Japan Earthquake (GEJE) and tsunami in the town of Ofunato in Iwate Prefecture. The compounded disasters in the GEJE took more than 18,500 lives, forced more than a quarter of a million people into temporary shelters, and shut down Japan's nuclear power plant program for several years.
Many of those in Tohoku whose homes were destroyed were forced to move into cramped, trailer-like spaces (similar to Federal Emergency Management Agency trailers) with limited privacy. In this environment, Ibasho was created to serve as a third space beyond home life and the workplace where people can socialize freely. ${ }^{13}$ The Ibasho building, which is a repurposed wooden farmhouse, provides a meeting space for local residents of all ages and regularly hosts programming focused on engaging children, adults, and the elderly. While Ibasho holds regular operation meetings among the community elders, it also emphasizes that it serves as an "ordinary place where everyone can come and go as they please, where they can be themselves, and can interact with other people."14

Before designing the building, our team discussed the project with the elders in the community and developed an operational plan based on their goals. Recognizing that many of the local residents saw themselves as people to be taken care of, rather than as active participants, we spent several months in spring 2012 working to develop a new community norm. Our team carried out workshops and engaged in group conversations to understand what local elderly disliked in their institutional care and to help them visualize themselves as leaders and change agents.

The commonly held vision of the community space revolved around informality where the elderly could enter and leave at whim. In that space, they would be able to undertake meaningful activities such as cooking, volunteering, storytelling for children, and teaching skills such as fire-starting that would allow them to take on the active roles of educators. The elderly also wanted to engage the younger members by creating a multigenerational learning community where both sides would benefit. The design that emerged from these community meetings embodied these goals and allowed the community to personalize the space as they saw fit. For example, rather than seeking to complete a perfectly finished building, we deliberately allowed many details to remain unfinished so that participants could add doors, space for children to play, and so forth.

Ibasho is open from 10 AM until 4 PM daily (except for Thursdays). Monthly group meetings decide future programming, volunteer schedules, and logistics for events. Rather than a yearly schedule of events, Ibasho is designed to organically allow different activities each month. Like other third spaces, the program is designed to allow for multiple concurrent activities. On some days we may find a group of local women knitting together with children playing nearby, while on other days there may be cooking classes for children and exercise classes for the elderly.

To analyze the impact of Ibasho on participants, we looked to 3 main outcomes of interest: (1) the number of friends participants reported; (2) the level of efficacy, that is, belief in their ability to change their environment; and (3) the sense 
of belonging to the neighborhood. These objective metrics sought to capture both the ties between residents and the ties between residents and their community. While we tested the impact that participation in the Ibasho program had on the wider community, we also recognized that various other factors may also play a role in determining those outcomes. To control for potentially confounding factors, we sampled a large portion of the local community in geographic areas far beyond the neighborhood of Massaki where Ibasho is located. We included information on age, gender, education, and income.

Scholars have argued that age is a deciding factor in whether people engage with each other and their communities. Typically, younger people are less likely than their older peers to vote, engage in community activities, and remain in a single community for an extended period. ${ }^{15}$ Middle-aged and elderly community members are often homeowners, not renters, and have longer tenures in their neighborhoods. At the same time, studies have argued that older people have fewer social interactions than do younger ones. ${ }^{16}$ Due to conflicting studies of age's role in civic engagement, we captured the effects of age by including a measurement of the respondent's age.

Next, Japan is a strongly gendered society, so in the same way that many have seen sex as influencing political behavior in that nation, it may influence patterns of social interaction and community engagement. ${ }^{17}$ Scholars have argued that women engage in political and social spheres differently than do their male counterparts. ${ }^{18}$ In Japan, women who define themselves as "housewives" typically have negative views of formal political leadership and instead engage in cooperatives, nonprofit organizations, volunteerism, and alternative forms of political engagement. ${ }^{19}$ Further, middle-aged and elderly women typically have left full-time employment to serve as caretakers for their children and their parents, putting them into different social environments than their husbands. Hence, we included gender in our regression to take into account different social behaviors possibly due to sex.

Beyond age and gender, educational achievement may strongly drive engagement in community and social networks. ${ }^{20}$ A number of studies have underscored that "class differences, especially those related to educational attainment, are prominent in political engagement of all kinds." ${ }^{21}$ Scholars have argued that education raises the benefits of civic engagement ${ }^{22}$ as more educated individuals have been socialized into social networks and norms. Recognizing this as a potential factor that can influence social network formation and maintenance, we included a measure of education in our regression.

A final characteristic of respondents that may impact their friendship networks, sense of belonging, and efficacy is income. One study of rural Tanzania found a relationship between income and levels of social capital, arguing that "social capital is an important, and so far largely missing, dimension of income and poverty analysis." 23 Other studies have found that income inequality - the gap between rich and poor-is strongly connected to a lack of social trust and group membership. ${ }^{24}$ Although many observers continue to see Japan as among the more equitable societies in terms of income, in fact its levels of inequality are on the rise. ${ }^{25}$ Wealthier individuals may have more leisure time and therefore more capacity to develop friends; at the same time, poorer individuals may need to develop social networks as substitutes for financial capital. Therefore, we included a measure of the respondents' incomes in our analysis.

\section{Data}

We worked with local organizations in the city of Ofunato along with volunteers to carry out 3 rounds of data collection in the city where Ibasho is located. We initially pilot tested a survey, approved by an IRB (\#15-10-33), in early 2013 on a small sample population of residents, nongovernmental organization members, and opinion leaders in the city of Ofunato, where the Ibasho project was planned. The responses from 25 individuals helped us to refine our survey and remove ambiguous language. The second round of data collection took place in the summer of 2013 (before the Ibasho facility opened) and provided a baseline sample of 599 respondents. Then, more than 1 year later in the fall of 2014 , we collected another round of surveys that captured data from 1142 respondents. We used geographic-based sampling to ensure that we would collect data from those most likely to participate in Ibasho-namely, those who lived closest to the facility in the neighborhood of Massaki-along with those less likely to do so, in neighborhoods several kilometers away. We had assistance from a number of local social welfare and educational organizations, including the Masaki elementary and middle schools, operators and managers of the temporary housing facilities (kasetsu jutaku), a local hospital, and also the municipal offices of the city. These organizations helped us deliver our paper-based survey to as wide a swath of the population as possible; we then coded the completed surveys into a machine-readable dataset. Our focus here was on the 2014 data that were collected nearly 1 year after the start of the Ibasho project.

Table 1 provides descriptive statistics for our 2014 sample across the city of Ofunato. The gender and age characteristics of our sample of more than 1000 people mirrored the broader makeup of the city of Ofunato. The vast majority of our sample had not visited the Ibasho project; this provided us with an excellent comparison group so that we could better identify the degree to which participation in the program correlated with outcomes of interest.

\section{METHODS}

To start our analysis, we carried out ordinary least squares regression analysis on the 3 outcomes of interest; the results of 


\section{Descriptive Statistics}

No. of Observations
Variables

1106

1095

1083

Efficacy

\section{Demographic characteristics}

Age category (18-29, 30-44, 45-59, 60-74, $\geq 75)$

Education level ( $1=$ middle school, $5=$ graduate degree $)$

Income category ( $1=<99 \mathrm{k}$ yen, $6=>6.5$ million $)$

Participation in Ibasho

Visits to Ibasho (categorical from none to daily)

\section{7}

1096

1064

799

1146
Gender ( 0 for women, 1 for men)
Mean

Mean

2.18
1.52
2.66

2.73
0.44
4.02
3.92

0.175393

SD

Min

$\operatorname{Max}$

1.04

0.63

1.03

1.09

0.50

1.38

1.65

0.686581

$\begin{array}{ll}0 & 4 \\ 0 & 2 \\ 0 & 4 \\ & \\ 1 & 5 \\ 0 & 1 \\ 1 & 8 \\ 1 & 6 \\ 0 & 6\end{array}$

these quantitative analyses are displayed in Tables A1 through A3 in the online data supplement. Briefly, with controls for age, gender, income, and educational level, those individuals who participated more regularly in Ibasho had a statistically significant level of difference in terms of efficacy, friendship network, and sense of belonging. While these initial results were supportive of our hypothesis, as is well known, standard regression analysis on observational data can only provide evidence of correlation between variables and not causation. The relationship may be reversed, so that people who already were more sociable attended more Ibasho events. Recognizing this methodological challenge, and to better understand potential causal relationships between variables of interest, we used an additional technique known as propensity score matching. ${ }^{26}$

Propensity score matching allowed us to better compare the respondents within our survey because it does not rely on model structure (as regression analysis does). Propensity score matching narrows down the total number of observations, eliminating those who, based on the dataset, would be less likely to have participated in the treatment (in this case, attending events at or going regularly to Ibasho). Using nearest neighbor matching, our comparison of similar individuals (in terms of cofounding factors such as income, age, education, and gender) who regularly went to Ibasho had statistically different levels of social ties and belonging. For example, among our smaller sample of matching subjects in propensity score matching, we found a 0.26 level of difference in efficacy and 0.43 in how many friends they reported. (Tables for these coefficients are available upon request.) The propensity score matching served as a double-check on our regression analyses and provided us with more confidence in our findings.

\section{RESULTS}

Having confirmed that the relationship illuminated by the ordinary least squares regression analysis was likely a causal one through our use of propensity score matching, we move on to

\section{FIGURE 1}

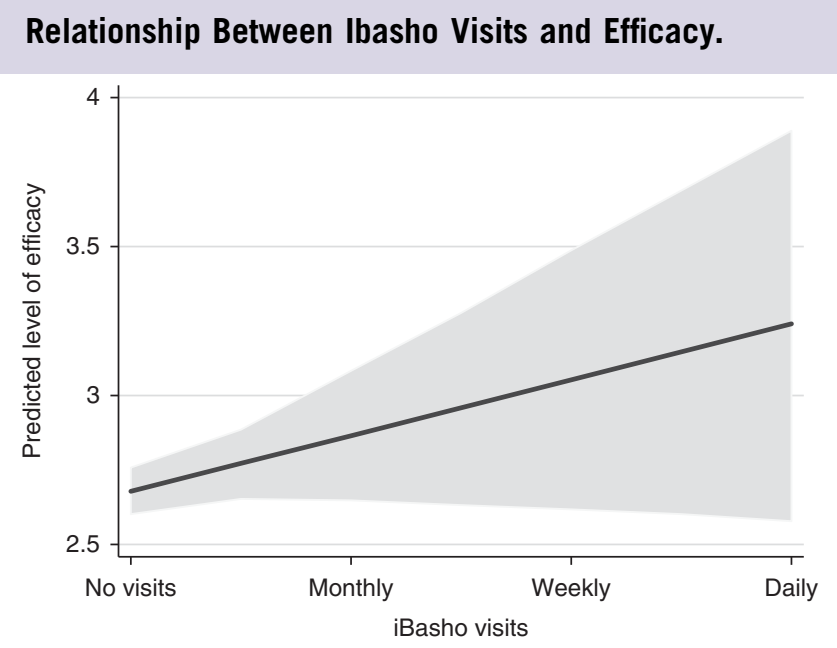

Note. The vertically shaded space represents the $95 \%$ confidence interval for the predicted level of efficacy for each respondent.

$N=750$, simulations $=1000$. All control variables (age, sex, income, and education) were held at their means while the number of Ibasho visits varied.

simulation and confidence intervals. Because of the challenges in interpreting the estimated coefficients from our regression analyses, we provide a more intuitive way to understand the connections between key variables of interest along with estimates of our uncertainties about those analyses. ${ }^{2}$

Figure 1 looks at the predicted relationship between our 2 core variables of interest: visits (or no visits) to the Ibasho facility and levels of efficacy, that is, belief that one can alter the environment nearby. We used our dataset to take random draws of individuals and then regressed the outcome on our full panel of controls and Ibasho visits. In this way we could show precisely how confident we are in our predictions. For example, for individuals living in Ofunato who reported never attending an event at Ibasho, we believe that their level of efficacy sits between 2.7 and 2.9. As individuals 


\section{FIGURE 2}

\section{Relationship Between Ibasho Visits and Number of Friends.}

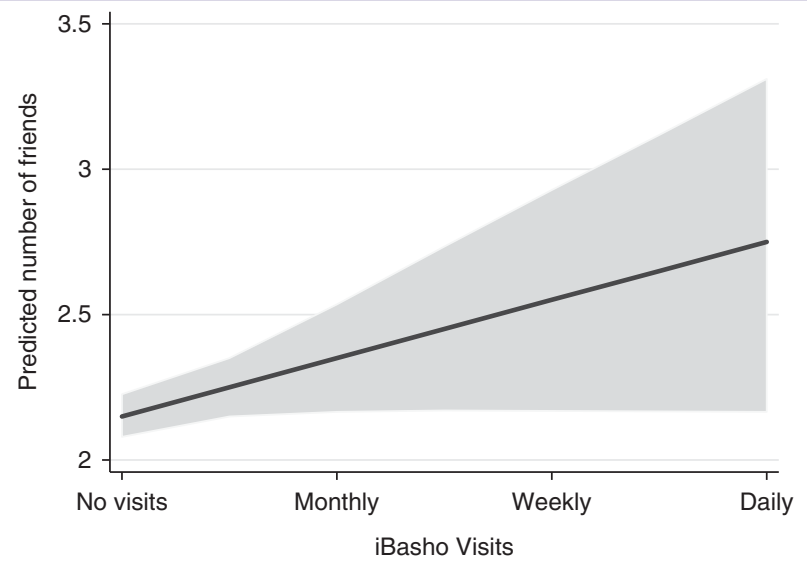

Note. The vertically shaded space represents the $95 \%$ confidence interval for the predicted number of friends for each respondent. $N=750$, simulations $=1000$. All control variables (age, sex, income, and education) were held at their means while the number of Ibasho visits varied.

participated more regularly in Ibasho-moving from never attending to yearly, monthly, weekly, and daily-we can see that this level of efficacy moved up noticeably. Hence, for someone who goes daily to Ibasho, some 70 members from our total sample, we would predict that their efficacy was close to 3.3, with a larger margin of error. Notice from our table of descriptive statistics that the average level of efficacy was roughly 2.6 with a standard deviation of 1 . Based on this larger sample, our daily participants at Ibasho sat a full standard deviation above the average in terms of their efficacy.

Next, we turn to the relationship between Ibasho visits and the number of reported friends as seen in Figure 2. Here again we held constant the various controls in our regressions (age, gender, income, and education) and allowed the Ibasho visits to vary. As before, we are most confident about our predictions for individuals who had no visits to Ibasho, as they were the most numerous in our sample. Therefore, the gray shaded space around those predictions near the left end of the $x$-axis is the smallest.

As individuals participated more regularly in Ibasho, they reported a higher number of friends, holding other factors constant. The typical respondent in our overall sample had roughly 2 friends. Our results showed that individuals who regularly attended events had roughly an additional friend beyond that average. As with our previous outcome of interest, this was a full standard deviation above the norm. Our final relationship of interest sought to understand how those who participated more (or less) often in Ibasho felt in terms of their belonging to their neighborhood. The average

\section{FIGURE 3}

\section{Relationship Between Ibasho Visits and Sense of Belonging to the Neighborhood.}

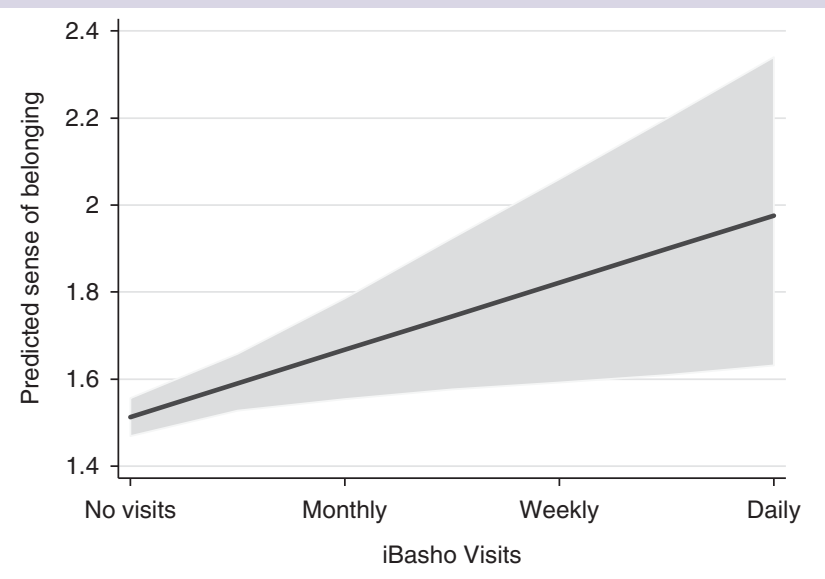

Note. The vertically shaded space represents the $95 \%$ confidence interval for the predicted level of sense of belonging to the neighborhood for each respondent. $N=750$, simulations $=1000$. All control variables (age, sex, income, and education) were held at their means while the number of Ibasho visits varied.

in our sample of some 1000 people was close to 1.5 ; this was the level that we predicted using our simulation for those who did not attend Ibasho as seen in Figure 3.

We can show that, as individuals participated more regularly in Ibasho, their sense of belonging increased almost a full standard deviation above the norm, controlling for gender, income, age, and education. Sense of efficacy was a critical predictor for civic engagement, as those who believed that they are taken seriously by decision-makers and that they can make a difference were more likely to participate in public meetings, express their opinion through formal channels like voting, and provide feedback to elected officials. Without such interaction, governments may be tempted to shortchange their citizens who in turn will disengage from the political sphere. ${ }^{6}$

\section{Limitations and Research Agenda}

Owing to the nature of the data that we collected, we had to rely not on outside observations of demographic characteristics and social capital levels of local residents but rather on self-reported data. Social scientists often use retrospective, self-reports of behaviors and norms when trying to understand critical outcomes. ${ }^{27}$ Here, we relied on the research carried out by past teams that have validated this type of self-reporting even for behaviors that may be impossible for outsiders to measure directly. ${ }^{28,29}$ We recognize that there may be some errors - either deliberate or inadvertent-in self-reporting, but have sought to design our surveys and data collection to minimize such problems. ${ }^{30}$ 
Our focus here has primarily been on issues of resilience and social interaction. However, public health specialists and epidemiologists might benefit from data focusing on issues such as physical and mental health and longevity among the elderly. Further, we have looked almost exclusively at measurable impacts within the elder community. It should be clear that the Ibasho serves a far wider population than those over the age of 55, and we would like to investigate how the program has impacted the mental and physical health of the children who participate regularly. We hope that scholars will be able to carry out future updates of our dataset that will incorporate such multigenerational and holistic measures.

\section{CONCLUSIONS}

This article sought to understand the degree to which a bottom-up, elder-managed intervention could both better integrate the elderly into society and create stronger resilience through enhanced levels of social capital. Our results, generated through a new dataset of more than 1000 respondents, show that the Ibasho project had measurable results in these 3 areas: efficacy, friends, and sense of belonging. Where typical approaches to the elderly envision them as a population to be managed and cared for, the Ibasho approach instead places them as managers and organizers for the local community. Individuals who are socially isolated and lonely are already at risk for higher rates of disease and mortality, ${ }^{31}$ and individuals who withdraw socially from friends and family similarly have more cognitive decline. ${ }^{32}$ Programs like Ibasho that seek to embed elderly survivors in their communities and engage them in day-to-day management of a facility may help combat these deleterious outcomes.

Our study of Ibasho joins the growing body of evidence that social capital, like other forms of capital, can be created and sustained through deliberate interventions. ${ }^{33,34}$ While we have focused on a single type of intervention, namely, designing a physical space with local elders in a post-disaster environment to enhance social ties, scholars have illuminated a number of other approaches, including mediator-led focus groups, community currency, and time banking. ${ }^{8}$ Building on these results, we would urge other nonprofit organizations, disaster managers, and program designers to think through the ways that their programs, whether focused on the elderly or not, can enhance social ties and therefore build resilience. ${ }^{35}$ At the very least, first responders and disaster managers should ensure that disaster mitigation measures, such as rapid but random assignment of survivors to temporary shelters, do not damage existing networks and further isolate victims.

Finally, we emphasize that the simplicity of the Ibasho approach and its relatively low cost (compared to technology-driven approaches or ones relying on massive infrastructure investment) suggest that it may be ideal for transport into other cultures and settings. Every society has a growing population of elderly whose experience and wisdom could be of use to younger generations.
The elderly are typically less likely to be engaged in full-time employment and also likely to be at risk for senility, dementia, and social withdrawal. Encouraging them to engage with a community building project can draw them out from this potential isolation and help enhance the overall community's resilience. Further, while the Ibasho project requires an extended time commitment, the small-scale nature of the project means that the relative costs for implementation are far lower than other comparable projects. Our Ibasho team is currently working with local elders on satellite projects in Philippines and Nepal that run on the same principles. We hope that, as our world enters an era of increased vulnerability to extreme weather and greater numbers of elderly, programs like Ibasho can serve as a vanguard to mitigate risks and enhance resilience.

\section{About the Authors}

Security and Resilience Studies Program, Department of Political Science, and School of Public Policy and Urban Affairs at Northeastern University, Boston, Massachusetts (Dr Aldrich), and Ibasho and Loeb Fellow, Graduate School of Design, Harvard University, Cambridge, Massachusetts (Dr Kiyota).

Correspondence and reprint requests to Prof. Daniel Aldrich, Department of Political Science, 215K Renaissance Park, 360 Huntington Avenue, Boston, MA 02115 (e-mail: daniel.aldrich@gmail.com).

\section{Acknowledgments}

We express our gratitude to the community of Massaki-cho, the city of Ofunato, the World Bank, and the Global Facility for Disaster Reduction and Recovery (GFDRR) for their assistance with this project. We also thank our colleague Yasuhiro Tanaka for his incredible devotion to Ibasho and Yuto Sakakibara for his research assistance.

\section{Funding}

This research was funded in part by the World Bank, Purdue University's Department of Political Science, Northeastern University, and the Fulbright Foundation. The funders had no role in study design, data collection, analysis, decision to publish, or preparation of this manuscript.

\section{Supplementary material}

To view supplementary material for this article, please visit https:/doi.org/10.1017/dmp.2016.206

Published online: January 23, 2017.

\section{REFERENCES}

1. EM-DAT. The International Disaster Database. http://www.emdat.be/. Accessed April 19, 2016.

2. King G, Tomz M, Wittenberg J. Making the most of statistical analyses: improving interpretation and presentation. Am J Pol Sci. 2000; 44(2):347-355. http://dx.doi.org/10.2307/2669316.

3. Nakagawa Y, Shaw R. Social capital: a missing link to disaster recovery. Int J Mass Emerg Disasters. 2004;22(1):5-34.

4. Kage R. Civic Engagement in Postwar Japan: The Revival of a Defeated Society. London: Cambridge University Press; 2010. http://dx.doi.org/ 10.1017/CBO9780511761409.

5. Chamlee-Wright E. The Cultural and Political Economy of Recovery: Social Learning in a Post-disaster Environment. New York: Routledge; 2010. 
6. Putnam R. Bowling Alone: Collapse and Revival of American Community. New York: Simon and Schuster; 2010.

7. Szreter S, Woolcock M. Health by association? Social capital, social theory, and the political economy of public health. Int J Epidemiol. 2004;33(4):650-667. http://dx.doi.org/10.1093/ije/dyh013.

8. Aldrich DP, Meyer M. Social capital and community resilience. Am Behav Sci. 2015;59(2):254-269. http://dx.doi.org/10.1177/ 0002764214550299.

9. Aldrich DP. Building Resilience: Social Capital in Post-Disaster Recovery. Chicago: University of Chicago Press; 2012. http://dx.doi.org/10.7208/ chicago/9780226012896.001.0001.

10. Klinenberg E. Heat Wave: A Social Autopsy of Disaster in Chicago. Chicago: University of Chicago Press; 2002. http://dx.doi.org/10.7208/ chicago/9780226026718.001.0001.

11. Aldrich DP, Sawada Y. The physical and social determinants of mortality in the 3.11 tsunami. Soc Sci Med. 2015;124:66-75. http://dx.doi.org/ 10.1016/j.socscimed.2014.11.025.

12. Kiyota E, Tanaka Y, Arnold M, Aldrich DP. Elders Leading the Way to Resilience. World Bank Group, Global Facility for Disaster Reduction and Recovery. https://www.gfdrr.org/sites/gfdrr/files/publication/Elders-Leadingthe-Way-to-Resilience.pdf. Published 2015. Accessed December 20, 2016.

13. Oldenburg R. The Great Good Place: Cafes, Coffee Shops, Bookstores, Bars, Hair Salons, and other Hangouts at the Heart of a Community. New York: Da Capo Press; 1999.

14. Ibasho. Ibasho Café Brochure. Ibasho website. http://www.ibasho.org/ web/resources/brochures.

15. Livingstone S, Couldry N, Markham T. Youthful steps towards civic participation: does the internet help? In: Loader B, ed. Young Citizens in the Digital Age: Political Engagement, Young People and New Media. London: Routledge; 2007:21-34.

16. McDonald S, Mair C. Social capital across the life course: age and gendered patterns of network resources. Sociol Forum. 2010; 25(2):335-359. http://dx.doi.org/10.1111/j.1573-7861.2010.01179.x.

17. Aldrich DP, Kage R. Mars and Venus at twilight: a critical investigation of moralism, age effects, and sex differences. Polit Psychol. 2003; 24(1):23-40. http://dx.doi.org/10.1111/0162-895X.00315.

18. Domingo P, Holmes R, O'Neil T, et al. Women's voice and leadership in decision making. London: Overseas Development Institute; 2015.

19. LeBlanc R. Bicycle Citizens: The Political World of the Japanese Housewife. Berkeley, CA: University of California Press; 1999.

20. Bourdieu P. The forms of capital. In: Richardson JG, ed. Handbook of Theory and Research for the Sociology of Education. New York, NY: Greenwood; 1985:241-258.

21. Smith A. Civic Engagement in the Digital Age. Pew Research Center. http://www.pewinternet.org/2013/04/25/civic-engagement-in-the-digitalage/. Published April 25, 2013. Accessed December 20, 2016.
22. Glaeser E, Ponzetto G, Shleifer A. Why does democracy need education? J Econ Growth. 2007;12(2):77-99. http://dx.doi.org/10.1007/s10887-0079015-1.

23. Narayan D, Pritchett L. Cents and sociability: household income and social capital in rural Tanzania. Econ Dev Cult Change. 1999; 47(4):871-897. http://dx.doi.org/10.1086/452436.

24. Kawachi I, Kennedy B, Lochner K, et al. Social capital, income inequality, and mortality. Am J Public Health. 1997;87(9):1491-1498. http://dx.doi.org/10.2105/AJPH.87.9.1491.

25. The Economist. February 14, 2015.

26. Ho D, Imai K, King G, et al. Matching as nonparametric preprocessing for reducing model dependence in parametric causal inference. Polit Anal. 2007;15(3):199-236. http://dx.doi.org/10.1093/pan/mpl013.

27. Holbrook A. Attitude change experiments in political science. In: Druckman J, ed. Cambridge Handbook of Experimental Social Science. New York: Cambridge University Press; 2011:252-279. 10.1017/ CBO9780511921452.010

28. Anglin MD, Hser Y-I, Chou C-P. Reliability and validity of retrospective behavioral self report by narcotics addicts. Eval Rev. 1993;17(1):91-108. http://dx.doi.org/10.1177/0193841X9301700107.

29. Svedberg P, Ropponen A, Lichtenstein P, et al. Are self-report of disability pension and long-term sickness absence accurate? Comparisons of self-reported interview data with national register data in a Swedish twin cohort. BMC Public Health. 2010;10(1):763. http://dx.doi.org/ 10.1186/1471-2458-10-763.

30. Krosnick J, Presser S. Question and questionnaire design. In: Handbook of Survey Research, 2nd ed. Bingley, United Kingdom: Emerald Group; 2010.

31. Steptoe A, Shankar A, Demakakos P, et al. Social isolation, loneliness, and all-cause mortality in older men and women. Proc Natl Acad Sci USA. 2013;110(15):5797-5801. http://dx.doi.org/10.1073/pnas. 1219686110.

32. Kawachi I, Berkman L. Social ties and mental health. J Urban Health. 2001;78(3):458-467. http://dx.doi.org/10.1093/jurban/ 78.3.458.

33. Pronyk PM, Harpham T, Busza J, et al. Can social capital be intentionally generated? A randomized trial from rural South Africa. Soc Sci Med. 2008;67(10):1559-1570. http://dx.doi.org/10.1016/j.socscimed. 2008.07.022.

34. Brune N, Bossert T. Building social capital in post-conflict communities: evidence from Nicaragua. Soc Sci Med. 2009;68(5):885-893. http://dx. doi.org/10.1016/j.socscimed.2008.12.024.

35. Wellington Region Emergency Management. It's Easy: Get Prepared for an Emergency. http://www.getprepared.org.nz/sites/default/files/uploads/ It's\%20Easy\%20Prepared\%20Households.pdf. Accessed December 20, 2016. 